\title{
A survey of preparedness against coronavirus disease 2019 (COVID-19) in hospitals in Tokyo, Japan, with healthcare personnel with COVID-19 and in-facility transmission
}

\author{
Yasuaki Tagashira MD, $\mathrm{PhD}^{1,2}$, Akane Takamatsu MD ${ }^{1,2}$, Shinya Hasegawa $\mathrm{MD}^{1}$, Yuki Uenoyama $\mathrm{CRIC}^{1}$ and \\ Hitoshi Honda MD, PhD $^{1}$ (i) \\ ${ }^{1}$ Division of Infectious Diseases, Tokyo Metropolitan Tama Medical Center, Tokyo, Japan and ${ }^{2}$ Department of Microbiology, Juntendo University Graduate School \\ of Medicine, Tokyo, Japan
}

\begin{abstract}
A questionnaire was distributed to hospitals in Tokyo $(\mathrm{N}=38)$ regarding their preparedness against and in-facility transmission of coronavirus disease 2019 (COVID-19). As of May 31, 2020, 284 HCP had contracted COVID-19, and in-facility COVID-19 transmission occurred at 13 hospitals, negatively impacting hospital functions and patient care.
\end{abstract}

(Received 4 August 2020; accepted 24 October 2020; electronically published 29 October 2020)

Healthcare personnel (HCP) are at much higher risk than the general population of contracting coronavirus disease 2019 (COVID19), despite advanced hospital infection control strategies. ${ }^{1}$ The Centers for Disease Control and Prevention in the United States reported that $\sim 500$ frontline HCP in the United States had died from COVID-19 by the end of July $2020 .^{2}$ In the present study, we used an Internet search to identify hospitals in Tokyo that issued press releases or held press conferences about their HCP who contracted COVID-19. Questionnaires were then distributed to these hospitals regarding their COVID-19 pandemic preparedness, routes of HCP infection, and resulting impacts on patient care and hospital functions.

\section{Methods}

\section{Study design}

The present study was based on responses to a questionnaire sent to hospitals in Tokyo, Japan, regarding HCP with COVID-19. ${ }^{3}$ The cumulative number of patients with laboratory-confirmed COVID-19 in Tokyo at the time of this study was $5,236 .{ }^{4} \mathrm{We}$ searched the websites of healthcare facilities that issued press releases or held press conferences regarding their HCP with COVID-19 between January 1, 2020, and May 31, 2020. We also searched the Internet for news about hospitals with infected HCP using the same key words. Overall, we identified 53 hospitals. The survey was conducted from June 4 to 17,2020 . The questionnaire collected the following information: (1) probable COVID-19

\footnotetext{
Author for correspondence: Hitoshi Honda, E-mail: hhhhonda@gmail.com

Cite this article: Tagashira Y, et al. (2021). A survey of preparedness against coronavirus disease 2019 (COVID-19) in hospitals in Tokyo, Japan, with healthcare personnel with COVID-19 and in-facility transmission. Infection Control \& Hospital Epidemiology, 42: 746-750, https://doi.org/10.1017/ice.2020.1304
}

transmission routes and outcomes, including clinical outcomes, in all the infected HCP and patients; (2) nosocomial transmission to inpatients and their clinical outcomes; (3) impact of COVID-19 transmission on hospital functions; (4) institutional preparedness against COVID-19; and (5) deleterious effects on hospital function related to the presence of infected HCP and nosocomial COVID-19 transmission. Nosocomial transmission was defined as in-facility COVID-19 onset, whereas community acquisition was defined as all other infections. The onset of infection was determined solely by the respondents.

\section{Results}

\section{Baseline information on hospitals with HCP with COVID-19}

Overall, 53 hospitals with HCP with COVID-19 were identified based on press releases, press conferences, or media reports. Among these, 38 (72\%) participated in our survey. Appendix 1 (online) shows their baseline characteristics.

In total, $284 \mathrm{HCP}$ in 38 hospitals contracted COVID-19. The median age of the infected HCP was 32 years (range, 20-81), and 211 (74\%) were female. Nurses accounted for 141 cases, and 155 personnel (55\%) were involved in caring for patients with COVID-19 before becoming infected. Although 22 of 38 (58\%) of the first HCP to become infected at each participating hospital were thought to have acquired the disease via community-onset infection, a large proportion of supervenient infections among HCP was thought to be due to nosocomial transmission (Table 1 and Appendix 2 online). Although 267 of these HCP (94\%) subsequently returned to work, 12 (4\%) were suspended or retired after contracting COVID-19.

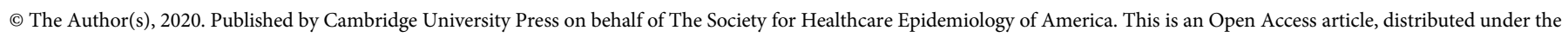

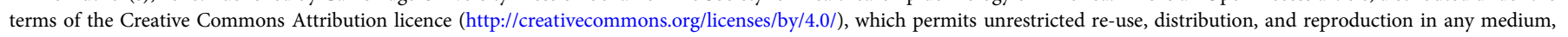
provided the original work is properly cited. 
Table 1. Details of Institutional Experiences for HCP and Patients With COVID-19

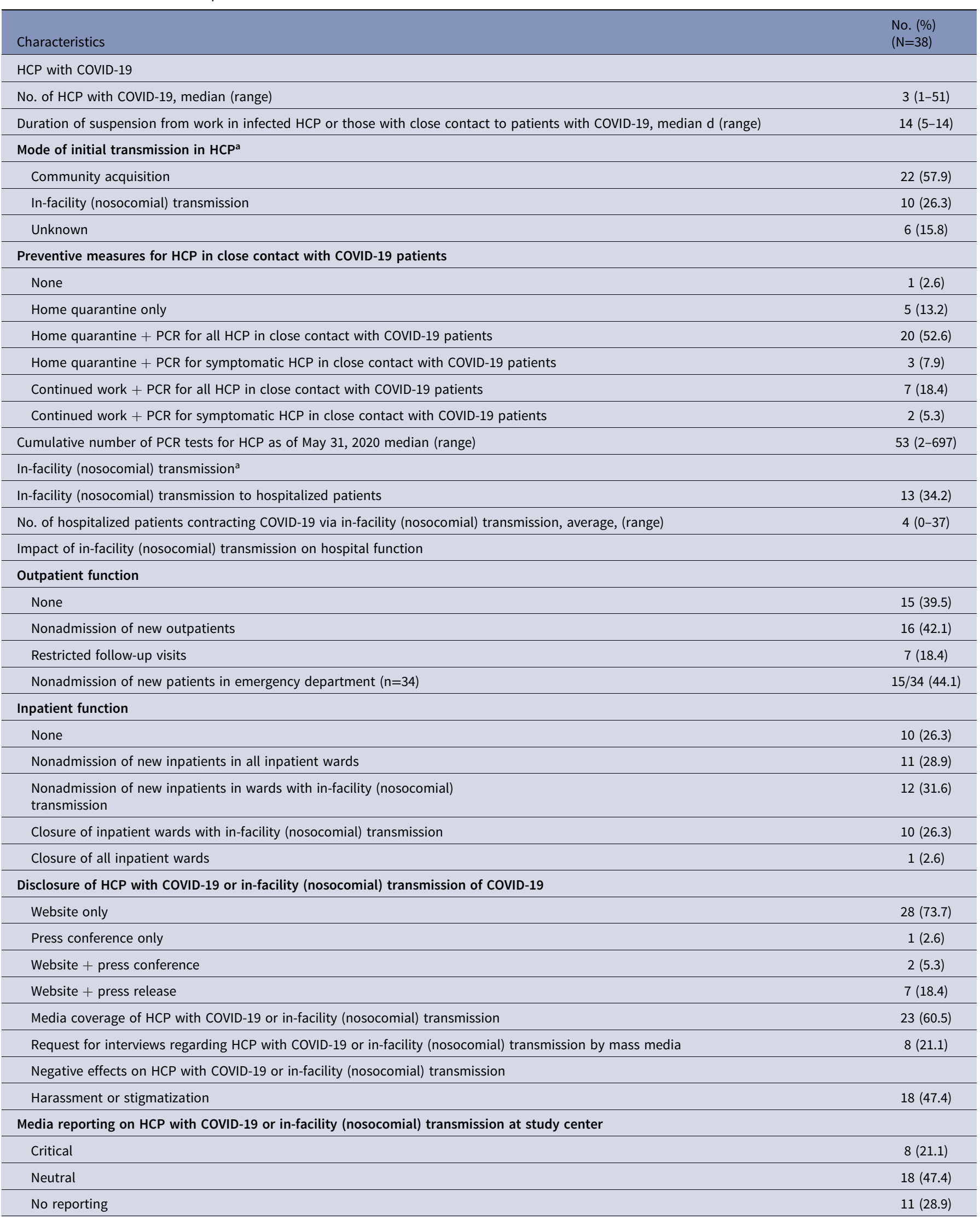


Table 1. (Continued)

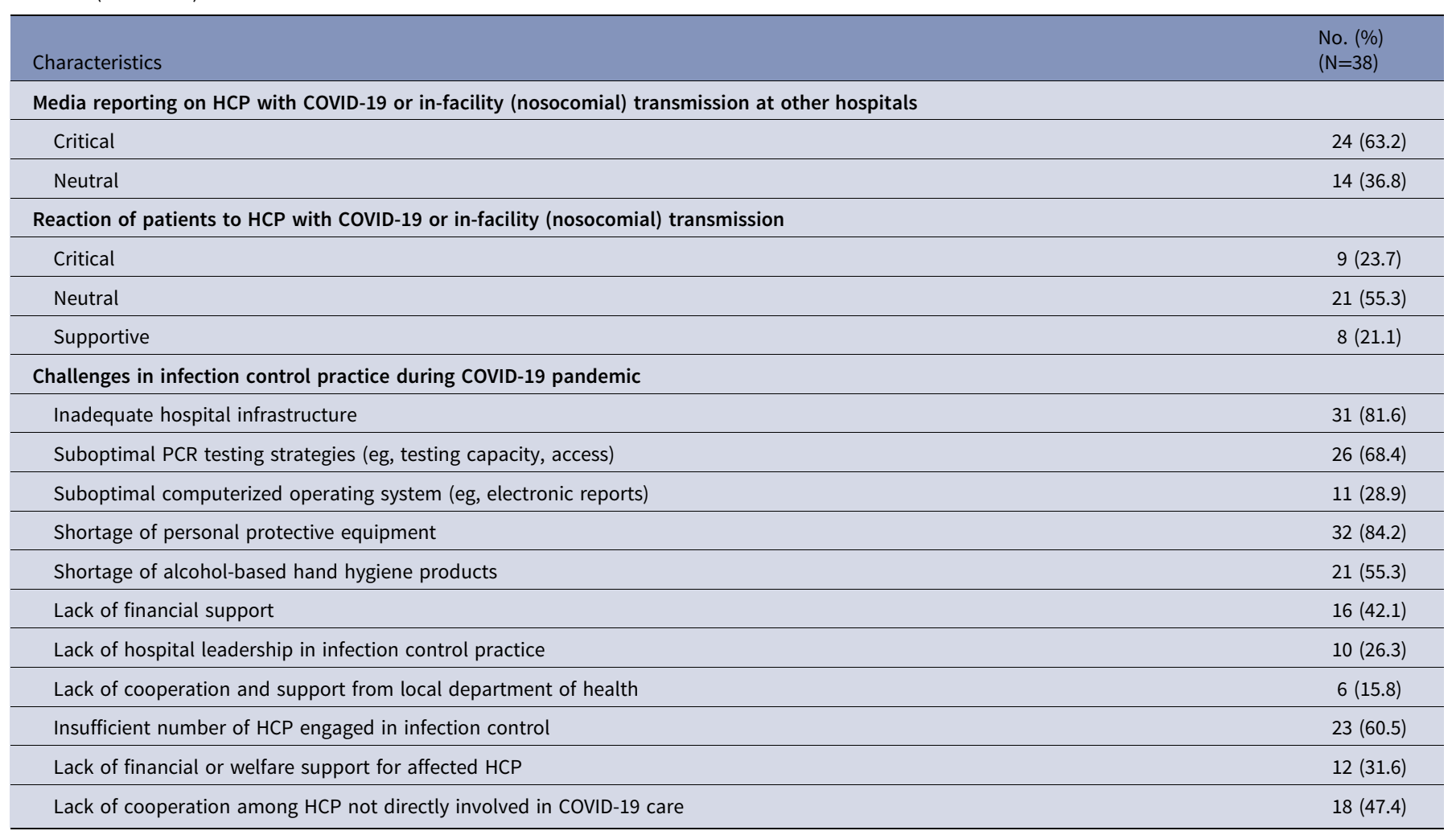

Note. HCP, healthcare personnel; COVID-19, coronavirus disease 2019.

asee 'Methods' for definition.

Impacts of COVID-19 transmission on HCP, inpatients, and hospital functions

Table 1 shows the details of the institutional experiences of healthcare personnel and patients with COVID-19. Nosocomial severe acute respiratory coronavirus virus 2 (SARS-CoV-2) transmission to inpatients occurred at 13 of the 38 hospitals (34\%). The total number of cases of nosocomial SARS-CoV-2 transmission to inpatients at the 13 hospitals reached 156, and 42 of these patients (27\%) died during hospitalization. Of the remaining 114 patients, only 21 of 156 (14\%) fully recovered, and 93 of 156 (60\%) continued to be hospitalized at the time of data collection.

At most of the hospitals, HCP with suspected exposure were removed from the front line until their negativity for SARSCoV-2 was confirmed, and HCP with suspected exposure in outpatient services $(23$ of $38,61 \%$ ) and inpatient services (28 of 38, $74 \%)$ were restricted or temporarily suspended. In addition, 18 hospitals (47\%) reported verbal abuse against both infected and noninfected HCP and their family members following reports of nosocomial SARS-CoV-2 transmission (Appendix 2 online). Moreover, a portion of the respondents felt that media reports negatively affected the functioning of their own hospital ( 8 of $38,21 \%)$ or other hospitals ( 24 of $38,63 \%$ ).

\section{Hospital preparedness for COVID-19 and association with in- facility COVID-19 transmission}

Table 2 compares preparedness for COVID-19 by the end of February 2020 among hospitals with or without nosocomial COVID-19 transmission. Hospitals with nosocomial transmission may have had less intensive hospital-level infection control practices, such as providing separate passages for patients with suspected COVID-19, or they may not have had a preparedness planning committee or hospital-specific COVID-19 guidance in place by the end of February 2020.

\section{Discussion}

By May 31, 2020, several hospitals in Tokyo reported nosocomial transmission of COVID-19 and infected HCP. As elsewhere, COVID-19 infections were common among HCP, who are at high risk of contracting the disease during patient treatment. ${ }^{5-7}$ Apparently, a common route of initial transmission among the HCP at each hospital was community rather than nosocomial transmission, with the remaining cases likely due to nosocomial transmission. In the early phase of the pandemic, close contact with patients with COVID-19 during routine patient care may have led to HCP infections, which might then have been transmitted through sharing common spaces during break times. ${ }^{8}$ Asymptomatic or minimally symptomatic cases among HCP can also result in transmission. ${ }^{9}$ Nosocomial transmission can also be exacerbated by shortages of personal protective equipment and alcohol-based sanitizers. ${ }^{10,11}$

Unfortunately, a high mortality rate among inpatients with COVID-19 due to nosocomial transmission was observed, in line with other reports. ${ }^{12}$ The findings of the present study underscored the importance of preventing the nosocomial transmission of COVID-19.

Moreover, the emergence of infections among HCP and the nosocomial transmission of COVID-19 further deleteriously affected patient care and hospital functions by producing various negative social effects, including verbal abuse of HCP by the public, criticism by the media, and negative patient responses (Appendix 3 
Table 2. Hospital Preparedness Against Nosocomial Transmission of COVID-19a

\begin{tabular}{|c|c|c|c|c|}
\hline Preparedness Achieved by the End of February 2020 & All & $\begin{array}{l}\text { Hospitals With } \\
\text { Nosocomial Transmission } \\
\text { ( } n=13) \\
\text { No. }(\%)\end{array}$ & $\begin{array}{l}\text { Hospitals Without } \\
\text { Nosocomial Transmission } \\
(\mathrm{n}=25) \\
\text { No. }(\%)\end{array}$ & $\begin{array}{c}P \\
\text { Value }\end{array}$ \\
\hline Organization of preparedness planning committee & 38 & $6(46.2)$ & $19(64.0)$ & .08 \\
\hline $\begin{array}{l}\text { Hospital-specific COVID-19 preparedness guidance (eg, hospital guide- } \\
\text { lines, manuals, etc) available to all HCP }\end{array}$ & 38 & $6(46.2)$ & $22(88.0)$ & .02 \\
\hline $\begin{array}{l}\text { Creation of separate passages for patients with suspected COVID-19 to } \\
\text { minimize cross contamination in emergency department }\end{array}$ & 34 & $2 / 11(18.2)$ & $17 / 23(73.9)$ & .004 \\
\hline $\begin{array}{l}\text { Creation of separate passages for patients with suspected COVID-19 to } \\
\text { minimize cross contamination in outpatient clinic }\end{array}$ & 38 & $5(26.3)$ & $17(73.9)$ & .01 \\
\hline $\begin{array}{l}\text { Creation of separate passages for patients with suspected COVID-19 for } \\
\text { admission to inpatient wards }\end{array}$ & 38 & $3(23.1)$ & $12(48.0)$ & .10 \\
\hline Restriction of visits to hospitalized patients & 38 & $9(69.2)$ & $16(64.0)$ & 1.00 \\
\hline Universal masking for all hospital visitors & 38 & $8(61.5)$ & $13(52.0)$ & 1.00 \\
\hline Universal masking for all HCP & 38 & $11(84.6)$ & $15(60.0)$ & .50 \\
\hline Designation of special wards for patients with COVID-19 & 38 & $4(30.8)$ & $10(40.0)$ & .73 \\
\hline Hospital-wide symptom reporting system for HCP & 38 & $8(61.5)$ & $12(48.0)$ & 1.00 \\
\hline
\end{tabular}

Note. SARS-CoV-2, severe acute respiratory syndrome coronavirus 2; COVID-19, coronavirus disease 2019; HCP, healthcare personnel.

${ }^{a}$ Facilities with nosocomial transmission were reported by the respondents.

online). Verbal abuse of infected HCP has been reported globally. ${ }^{13-15}$ Changes in the public mindset and improved understanding of COVID-19 transmissibility are needed to eliminate this sort of behavior. ${ }^{14}$

In general, inadequate hospital preparedness during the early phase of the pandemic was likely associated with nosocomial COVID-19 transmission. The community spread of COVID-19 began in February 2020, and hospital preparedness by the end of February 2020 serves as an important index of the preparedness mindset prior to the surge in infections. The preparedness planning and organization of committees at the hospitals in this study demonstrated the generally proactive efforts of the hospital leadership. The availability of hospital-wide guidelines to deal with COVID-19 and prompt implementation of infection control practices reflected the general competence of the infection control departments. Moreover, other hospital-wide measures, such as providing special passages for patients with suspected COVID19 to minimize potential facility-wide contamination, were more common among hospitals without nosocomial transmission.

This study has several limitations. The exact mode of transmission to either HCP or inpatients was unable to be determined due to the lack of a clear definition of nosocomial transmission and community-onset COVID-19 infection. Because the determinations of the transmission mode and infection onset were made by individual infection control personnel and were self-reported by the facility, the data were not validated. Moreover, because the questionnaire depended completely on the respondents' impression and reports, a response bias may have been introduced. Finally, our study focused solely on hospitals in Tokyo; thus, the findings may not reflect the situation elsewhere.

In conclusion, COVID-19 transmission among HCP and nosocomial transmission to inpatients was common and negatively affected hospital functioning and patient care. Furthermore, to preserve the safety and dignity of HCP with COVID-19, changes in the public's mindset and better understanding of the transmissibility of COVID-19 are needed.
Supplementary material. To view supplementary material for this article, please visit https://doi.org/10.1017/ice.2020.1304

Acknowledgments. We are indebted to James R. Valera for his assistance with editing the manuscript. We thank all the questionnaire respondents for their participation.

Financial support. No financial support was provided relevant to this article.

Conflicts of interest. All authors report no conflicts of interest relevant to this article.

\section{References}

1. Adams JG, Walls RM. Supporting the health care workforce during the COVID-19 global epidemic. JAMA 2020;323:1439-1440.

2. Cases in the United States. US Centers for Disease Control and Prevention website. https://www.cdc.gov/coronavirus/2019-ncov/cases-updates/casesin-us.html. Accessed October 27, 2020.

3. Tokyo Metropolitan Government, Bureau of Social Welfare and Public Health website. https://www.fukushihoken.metro.tokyo.lg.jp/chosa/index. html. Accessed June 24, 2020.

4. Tokyo metropolitan COVID-19. Tokyo Metropolitan Government website. https://stopcovid19.metro.tokyo.lg.jp. Accessed June 24, 2020.

5. Cheng VC, Wong SC, Yuen KY. Estimating coronavirus disease 2019 infection risk in healthcare workers. JAMA Netw Open 2020;3:e209687.

6. Bays DJ, Nguyen MH, Cohen SH, et al. Investigation of nosocomial SARSCoV-2 transmission from two patients to healthcare workers identifies close contact but not airborne transmission events. Infect Control Hosp Epidemiol 2020. doi: $10.1017 /$ ice.2020.321.

7. Sikkema RS, Pas SD, Nieuwenhuijse DF, et al. COVID-19 in healthcare workers in three hospitals in the south of The Netherlands: a cross-sectional study. Lancet Infect Dis 2020;20:1273-1280.

8. Furuse Y, Sando E, Tsuchiya N, et al. Clusters of coronavirus disease in communities, Japan, January-April 2020. Emerg Infect Dis 2020;26: 2176-2179.

9. Arons MM, Hatfield KM, Reddy SC, et al. Presymptomatic SARS-CoV-2 infections and transmission in a skilled nursing facility. $N$ Engl J Med 2020;382:2081-2090 
10. Ranney ML, Griffeth V, Jha AK. Critical supply shortages-the need for ventilators and personal protective equipment during the COVID-19 pandemic. N Engl J Med 2020;382:e41.

11. Grimm CA. Hospital experiences responding to the COVID-19 pandemic: results of a National Pulse survey March 23-27, 2020. US Department of Health and Human Services website. https://oig.hhs.gov/oei/reports/oei06-20-00300.pdf. Accessed July 20, 2020.

12. Rickman HM, Rampling T, Shaw K, et al. Nosocomial transmission of COVID-19: a retrospective study of 66 hospital-acquired cases in a London teaching hospital. Clin Infect Dis 2020. doi: 10.1093/cid/ciaa816.
13. Discrimination of healthcare workers due to coronavirus 'disgraceful.' Channel News Asia (CNA) website. https://www.channelnewsasia.com/ news/singapore/wuhan-virus-coronavirus-covid19-discrimination-healthcareworker-12426528. Accessed July 20, 2020.

14. Honda H. It's not you versus us, it's us versus the virus. Infect Control Hosp Epidemiol 2020. doi: 10.1017/ice.2020.258.

15. Coronavirus: St Austell NHS worker verbally abused by neighbour. BBC News website. https://www.bbc.com/news/uk-england-cornwall52126513. Accessed July 20, 2020. 